JSI 9 (1) (2020)
Jurnal Sastra Indonesia
UNNES

\title{
SATUAN-SATUAN LINGUAL DALAM TRADISI NGALUNGI DI DESA SEKARSARI KECAMATAN SUMBER KABUPATEN REMBANG: KAJIAN ETNOLINGUISTIK
}

\section{Umi Nur Sholikhah ${ }^{\varpi 1}$ dan Hari Bakti Mardikantoro ${ }^{2}$}

Program Studi Sastra Indonesia, Jurusan Bahasa dan Sastra Indonesia, Fakultas Bahasa dan Seni, Universitas Negeri Semarang, Indonesia

\begin{tabular}{|c|c|}
\hline Info Artikel & Abstrak \\
\hline $\begin{array}{l}\text { Sejarah Artikel: } \\
\text { Diterima Oktober } 2019 \\
\text { Disetujui Februari } 2020 \\
\text { Dipublikasikan Maret } 2020\end{array}$ & $\begin{array}{l}\text { Penelitian ini bertujuan untuk menjelaskan bentuk, makna kultural, dan fungsi satuan- } \\
\text { satuan lingual yang terdapat dalam tradisi Ngalungi Sapi di Desa Sekarsari, Kecamatan } \\
\text { Sumber, Kabupaten Rembang. Pendekatan yang digunakan dalam penelitian ini ada } \\
\text { dua jenis, yakni pendekatan teoretis dan pendekatan metodologis. Pendekatan teoretis } \\
\text { menggunakan pendekatan etnolinguistik, sedangkan pendekatan metodologis yaitu }\end{array}$ \\
\hline $\begin{array}{l}\text { Keywords: } \\
\text { cultural means, lingual } \\
\text { units, Ngalungi Sapi } \\
\text { tradition }\end{array}$ & $\begin{array}{l}\text { 1) bentuk-bentuk satuan lingual yang terdapat dalam tradisi Ngalungi Sapi meliputi } \\
\text { kata, frasa, klausa, kalimat, dan wacana, 2) secara garis besar makna kultural dari } \\
\text { tradisi Ngalungi Sapi yaitu sebagai wujud rasa syukur para petani kepada Tuhan atas } \\
\text { rezeki yang telah diberikan berupa hasil panen padi. Sapi sebagai raja kaya telah } \\
\text { membantu petani selama masa tanam. Maka dari itu, dibuatkanlah ketupat dan lepet } \\
\text { sebagai sajian utama dalam tradisi ini, 3) fungsi satuan-satuan lingual dalam tradisi } \\
\text { Ngalungi Sapi meliputi sarana ritual, wujud doa dan harapan, menamai bahan-bahan } \\
\text { masakan, dan menamai proses memasak. }\end{array}$ \\
\hline
\end{tabular}

\begin{abstract}
This study aims to explain the shape, cultural meaning, and function of lingual units found in the Ngalungi Sapi tradition in Sekarsari Village, Sumber District, Rembang Regency. There are two approaches used in this study, theoretical and methodological. Theoretical approach uses an ethnolinguistic approach, and the methodological approach is by qualitative ethnographic descriptive method. The results of this research can be published first, is the units of language available in the Ngalungi Sapi tradition, words, phrases, clauses, sentences, and discourses. Secondly the outline of cultural meaning in Ngalungi Sapi Tradition is a form of gratitude from the farmers to God for the fortune that has been given in the form of rice yields. Cows as Raja Kaya has helped farmers during the planting period. Third, the functions of the lingual units in the Ngalungi Sapi tradition include ritual means, forms of prayer and hope, naming food ingredients, and cooking process.
\end{abstract}

(C) 2020 Universitas Negeri Semarang

Alamat korespondensi:

ISSN 2252-6315

Gedung B1 Lantai 1 FBS Unnes

Kampus Sekaran, Gunungpati, Semarang, 50229

E-ISSN 2685-9599

E-mail: ummy.sholikhah13@mail.unnes.ac.id 


\section{PENDAHULUAN}

Masyarakat Jawa merupakan suatu kesatuan masyarakat yang diikat oleh normanorma hidup karena sejarah, tradisi, maupun agama (Amin dalam Safitri 2014:1). Banyak budaya dari suku Jawa yang dapat dijumpai, salah satunya terdapat di desa Sekarsari. Desa yang sebagian besar penduduknya berprofesi sebagai petani ini memiliki tradisi khusus yang dilakukan menjelang masa tanam padi tiba. Tradisi ini dinamakan Ngalungi/Ngalungi Sapi.

Dalam masyarakat agraris terutama di Jawa, tradisi penghormatan terhadap Dewi Sri menjadi simbol dan kerangka acuan berpikir bagi orang Jawa khususnya petani Jawa di dalam prosesi siklus hidup yaitu perkawinan, memperlakukan rumah dan tanah pertaniannya (Kamsiadi dkk 2013:65). Salah satu wujud penghormatan tersebut terdapat pada tradisi Ngalungi Sapi. Sesuai dengan namanya, ritual pada tradisi Ngalungi Sapi ini ditujukan kepada sapi. Namun di desa Sekarsari tidak demikian, warga juga melakukan ritual itu untuk kambing atau hewan-hewan yang dianggap sebagai raja kaya.

Pada pelaksanaan tradisi Ngalungi Sapi, warga yang memelihara sapi wajib membuat kupat dan lepet. Pelaksanaan tradisi ini pun tidak sembarang hari, ada hari-hari tertentu yang dipercayai warga sebagai hari baik. Menurut mbah Lamijan (70), hari baik tersebut jatuh pada Jumat Pahing, Rabu Pahing dan Selasa Kliwon. Saat hari perayaan tiba, warga akan melakukan kenduri yang dilanjutkan dengan ritual Ngalungi Sapi.

Awal mulanya ritual Ngalungi Sapi ini dilakukan di ndong gedhe yang dipercayai warga sebagai tempat sakral. Ketika malam hari tiba, warga yang memiliki sapi bersama-sama menuju ndong gedhe. Mereka membawa dunak atau baskom yang berisi ketupat dan lepet serta dhadhung (tali yang biasa digunakan warga untuk mengikat sapi) tidak lupa pula uang recehan sebagai wajid. Setelah semuanya berkumpul, acara akan dipimpin oleh seorang modin (tokoh agama desa). Kemudian modin tersebut akan membacakan doa-doa dan ketika semuanya selesai, warga yang hadir membagikan kupat dan lepet mereka kepada orang-orang yang ikut serta.

Seiring berjalannya waktu, warga silih berganti dan mulai melek dengan adanya perkembangan budaya sehingga beberapa bagian dari tradisi Ngalungi Sapi mengalami pergantian atau penyesuaian. Hal ini sejalan dengan apa yang dikatakan Kluckhon (dalam Purwanto 2013: 132) bahwa para petani selalu beraktifitas untuk mencapai tujuannya dengan cara menyesuaikan nilai-nilai budaya yang sudah terpelihara di masyarakat. Aktivitas tersebut berkaitan dengan ritus, bahasa, kesenian, ilmu pengetahuan dan teknologi.

Salah satu hal lain yang mengalami perubahan dalam tradisi Ngalungi Sapi yaitu tempat pelaksanaan ritual yang semula bertempat di ndong gedhe, sekarang beralih ke rumah masing-masing warga. Modin yang biasa memimpin doa bisa mereka undang ke rumah atau juga dapat digantikan dengan orang yang dianggap mampu untuk memimpin doa tersebut.

Dengan adanya pengaruh serta perubahan yang terjadi, secara otomatis sedikit banyak akan berpengaruh pula pada satuan-satuan lingual tradisi Ngalungi Sapi.

Satuan lingual tradisi Ngalungi Sapi yang digunakan masyarakat desa Sekarsari sendiri, mengandung makna simbolis yang mencerminkan budaya yang ada di dalam desa tersebut. Misalnya terlihat dari kata wajid [wajId].

Wajid [wajId] merupakan kata yang berasal dari bahasa Jawa yang berarti uang, baik receh ataupun bukan, yang biasa diberikan bersamaan dengan berkat/makanan ketika masyarakat yang bersangkutan mengadakan hajat. Kata wajid dalam tradisi Ngalungi Sapi memiliki makna sebagai uang pengganti. Sebagaimana fungsinya, uang digunakan sebagai alat pembayaran. Maksudnya, jika dalam memberikan sesaji ada kekurangan maka dengan adanya wajid tersebut diharapkan dapat menggantikannya.

Satuan lingual berbentuk kata tersebut dapat menggambarkan kebudayaan masyarakat desa Sekarsari. Oleh karena itu, sudah selayaknya tradisi ini dilestarikan. Mengingat saat ini sangat mudah budaya asing yang masuk ke dalam kehidupan kita. Fenomena tersebut diperkuat dengan banyaknya pemuda desa yang silih berganti menjadi perantau di luar daerah, sehingga tidak menutup kemungkinan bagi mereka untuk membawa pengaruh baru ke dalam tradisi Ngalungi Sapi.

Melalui kontak budaya seperti itu, tradisi dan kebudayaan akan terus berkembang dan mengalami perubahan. Perkembangan tersebut juga berdampak pada satuan-satuan lingual yang terdapat dalam tradisi Ngalungi Sapi.

Terdapat beberapa penelitian yang relevan yaitu penelitian yang dilakukan oleh Alip Sugianto pada tahun 2015 yang berjudul "Gaya Bahasa dan Budaya Mantra Warok Reyog Ponorogo (Kajian Etnolinguistik)". Dari hasil penelitian tersebut dapat diketahui bahwa secara etnolinguistik dengan memahami bahasa mantra 
warok, maka ditemukan pemahaman budaya warok tentang dunianya, yaitu reyog Ponorogo beserta aspek-aspek yang melingkupinya.

Penelitian yang dilakukan oleh Yogi Arton Marawiranu pada tahun 2016 yang berjudul "Produk Kata-Kata Industri Kreatif Cak Cuk Kata Kota Kita: Kajian Etnolinguistik". Dari hasil penelitian tersebut dapat diketahui bahwa dengan kajian etnolinguistik, penelitian tersebut mendeskripsikan tentang karakter masyarakat Surabaya pada suvenir Cak Cuk Kata Kota Kita yang menggambarkan bahasa dan budaya masyarakat Surabaya.

Penelitian yang dilakukan oleh Wahyu Fitrianingrum pada tahun 2016 yang berjudul "Bahasa dalam Budaya Jawa Terkait Aktivitas Pertanian Padi di Desa Bangsri Kecamatan Karangpandan Kabupaten Karanganyar (Kajian Etnolinguistik)". Dari hasil penelitian tersebut dapat diketahui bahwa dengan kajian etnolinguistik ditemukan istilah terkait aktivitas dan sebelum dan saat menanam padi. Istilah tersebut dikelompokkan menjadi bentuk monomorfemis, polimorfemis berupa afiksasi dan kata ulang, bentuk frasa, dan bentuk klausa.

Penelitian yang dilakukan oleh Devita Maliana Sari pada tahun 2017 yang berjudul "Nilai Filosofis dalam Leksikon Batik Demak di Kabupaten Demak (Kajian Etnolinguistik)". ". Dari hasil penelitian tersebut dapat diketahui bahwa dengan kajian etnolinguistik, terdapat 70 leksikon batik Demak yang digunakan oleh pengrajin batik Demak. Leksikon batik Demak terdiri atas dua klasifikasi yaitu berdasarkan kategori satuan lingual dan berdasarkan kategori bentuk.

Penelitian yang dilakukan oleh Muhammad Sukri pada tahun 2018 yang berjudul "Leksikon dalam Adat Perkawinan Masyarakat Suku Sasak di Kabupaten Lombok Utara: Sebuah Kajian Etnolinguistik”. Dari hasil penelitian tersebut dapat diketahui bahwa dengan kajian etnolinguistik penelitian tersebut dapat menunjukkan adanya perubahan dan pergeseran bahasa yang terjadi pada masyarakat suku Sasak terutama pada adat perkawinan masyarakat setempat.

Penelitian yang dilakukan oleh Ari Wulandari, dkk pada tahun 2018 yang berjudul "Pandangan Penutur Bahasa Jawa Terhadap Cacar". Dari hasil penelitian tersebut dapat diketahui bahwa dengan kajian etnolinguistik dapat mendeskripsikan klasifikasi penyakit cacar dan pengobatannya dari cara pandang orang Jawa.

Penelitian yang dilakukan oleh Puspa Endah Setiani, dkk pada tahun 2018 yang berjudul "Leksikon Anyaman Bambu di Kecamatan Pacet Kabupaten Bandung (Kajian Etnolinguistik). Dari hasil penelitian tersebut dapat diketahui bahwa dengan kajian etnolinguistik dapat mengetahui leksikon anyaman bambu yang terdapat di kecamatan Pacet kabupaten Bandung yang diklasifikasikan berdasarkan fungsinya, yaitu alat dapur, alat rumah tangga, alat pertanian, alat perikanan, dan alat bangunan rumah.

Penelitian yang dilakukan oleh Siti Komariyah pada tahun 2018 yang berjudul "Leksikon Peralatan Rumah Tangga Berbahan Bambu di Kabupaten Magetan (Kajian Etnolinguistik)". Dari hasil penelitian tersebut dapat diketahui bahwa dengan kajian etnolinguistik dapat mengetahui sejumlah leksikon peralatan rumah tangga berbahan bambu yang berbentuk monomorfemis, polimorfemis, kata ulang, dan frasa.

Penelitian yang dilakukan oleh $\mathrm{Ni}$ Nengah Suarsini pada tahun 2018 yang berjudul "Tradisi Ngelawang pada Hari Raya Kuningan di Desa Pakraman Asak Pagutan: Sebuah Kajian Etnolinguistik". Dari hasil penelitian tersebut dapat diketahui bahwa dengan kajian etnolinguistik dapat mengetahui perbedaan konsep dan prosesi tradisi Ngelawang di Desa Pakraman Asak Pagutan dengan yang dilakukan di Bali. Istilah yang digunakan dalam ritual tersebut dikelompokkan dalam bentuk monomorfemis, dan polimorfemis (afiksasi, komposisi, dan reduplikasi).

Penelitian yang dilakukan oleh Listi Hanifah, dkk pada tahun 2019 yang berjudul "Bentuk Istilah-Istilah Upacara Panggih Pernikahan Adat Jawa: Kajian Etnolinguistik". Dari hasil penelitian tersebut dapat diketahui bahwa dengan kajian etnolinguistik dapat mengetahui bentuk istilah yang terdapat dalam upacara panggih pernikahan adat Jawa adalah kata, frasa, dan klausa.

Dengan demikian, tujuan penelitian ini adalah mendeskripsikan bentuk, makna budaya, dan fungsi satuan-satuan lingual dalam tradisi Ngalungi Sapi di Desa Sekarsari Kecamatan Sumber, Kabupaten Rembang.

\section{METODE PENELITIAN}

Pendekatan yang digunakan dalam penelitian ini ada dua jenis, yakni pendekatan teoretis dan pendekatan metodologis. Pendekatan teoretis yang digunakan adalah pendekatan etnolinguistik. Menurut Putra (dalam Purwanti 2018:46), metode etnolinguistik bertujuan untuk mengkaji bahasa suatu masyarakat karena bahasa merupakan 
pandangan hidup suatu masyarakat. Selain itu, kajian tentang bahasa dan maknanya akan memungkinkan peneliti untuk mengetahui cara pandang kenyataan yang ada di kalangan pendukung bahasa yang diteliti tersebut. Artinya, peneliti dapat mengetahui dimensi-dimensi kenyataan yang menurut suatu masyarakat penting dalam kehidupan.

Pendekatan metodologis yang digunakan adalah metode deskriptif kualitatif etnografi. Berdasarkan Aminudin (dalam Sari 2006:40) metode deskriptif kualitatif artinya, data yang dianalisis dan hasil analisisnya berbentuk deskripsi fenomena, tidak berupa angka-angka atau koefisien tentang hubungan antar variabel. Tujuan digunakannya metode kualitatif yaitu untuk mempelajari budaya dalam tradisi Ngalungi Sapi di desa Sekarsari, Kecamatan Sumber, Kabupeten Rembang, sedangkan metode deskriptif digunakan untuk menganalisis data yang berupa satuan lingual dalam tradisi Ngalungi Sapi, sehingga hasil analisisnya berupa gambaran mengenai satuan-satuan lingual tersebut.

Data dalam penelitian ini berupa satuansatuan lingual berbentuk kata, frasa, klausa, dan penggalan wacana yang digunakan oleh masyarakat desa Sekarsari dalam tradisi Ngalungi Sapi. Sumber data dalam penelitian ini berwujud wacana yang berupa tuturan dari informan pilihan yang mengandung satuan-satuan lingual dalam tradisi Ngalungi Sapi di desa Sekarsari, Kecamatan Sumber, Kabupaten Rembang.

Pengumpulan data dalam penelitian ini yang pertama menggunakan metode simak dengan teknik dasarnya yaitu teknik sadap. Untuk teknik lanjutannya berupa teknik simak libat cakap, teknik rekam dan teknik catat. Metode yang kedua yaitu metode cakap dengan teknik dasar yang digunakan adalah teknik pancing serta teknik lanjutannya menggunakan teknik cakap semuka.

Pada penelitian ini data yang terkumpul dianalisis menggunakan metode agih dengan teknik pilah unsur langsung dan metode padan dengan teknik pilah unsur penentu.

Sudaryanto (dalam Fauza 2010: 43) menyatakan, metode distribusional (distributional method) disebut juga dengan metode agih. Metode distribusional adalah metode analisis data yang alat penentunya berupa unsur dari bahasa itu sendiri. Metode ini digunakan untuk menganalisis satuan-satuan lingual dalam tradisi Ngalungi Sapi di desa Sekarsari. Teknik pilah unsur langsung digunakan untuk memilah data yang dibutuhkan yaitu berupa kata, frasa, klausa, dan penggalan wacana yang terdapat pada satuan-satuan lingual dalam tradisi Ngalungi Sapi.

Kemudian untuk mengetahui makna kultural atau budaya yang tercermin dalam tradisi Ngalungi Sapi ini, peneliti menggunakan metode padan karena peneliti menghubungkan bahasa dengan hal yang berada di luar bahasa, yaitu budaya. Selanjutnya menggunakan teknik pilah unsur penentu yaitu teknik analisis data dengan cara memilah-milah satuan kebahasaan yang dianalisis dengan alat penentu yang berupa daya pilah yang bersifat mental yang dimiliki oleh penelitinya (Kesuma 2007:51).

Penyajian hasil analisis data pada penelitian ini menggunakan metode formal dan metode informal. Metode formal digunakan karena dalam penelitian ini menyajikan leksikon dalam transkrip fonetis dengan menggunakan tanda kurung. Metode informal digunakan karena peneliti mendeskripsikan makna kultural dari tradisi Ngalungi Sapi di desa Sekarsari, Kecamatan Sumber, Kabupaten Rembang.

\section{HASIL DAN PEMBAHASAN}

Berdasarkan penelitian lapangan yang telah dilakukan oleh peneliti, ditemukan satuansatuan lingual yang berkaitan dengan tradisi Ngalungi Sapi di desa Sekarsari.

\section{Bentuk Satuan Lingual Tradisi Ngalungi Sapi Kata}

Bloomfield (dalam Chaer 2003:163) menyatakan bahwa kata adalah satuan bebas terkecil (a minimal free form) tidak pernah diulas atau dikomentari, yang seolah-olah batasan itu sudah bersifat final.

Satuan lingual yang berbentuk kata benda (nomina) dalam tradisi Ngalungi Sapi berjumlah 20 data yang diuraikan sebagai berikut.

\section{Tabel 1. Satuan Lingual Berbentuk Kata}

$$
\text { Benda }
$$

\begin{tabular}{|c|c|c|}
\hline No. & Kata & Fonetik \\
\hline 1. & janur & [janUr] \\
\hline 2. & beras & [boras] \\
\hline 3. & ketan & 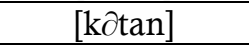 \\
\hline 4. & kelapa & [kdlapa] \\
\hline 5. & wose & [wose] \\
\hline 6. & uyah & [uyah] \\
\hline 7. & besek & [besc?] \\
\hline 8. & urang & [uran] \\
\hline 9. & tahu & [tahu] \\
\hline 10. & endhog & [2ndhog] \\
\hline 11. & mihun & [mihun] \\
\hline 12. & pete & [pote] \\
\hline 13. & santen & {$[\operatorname{sant} \partial \mathrm{n}]$} \\
\hline 14. & kecap & [kecap] \\
\hline 15. & empon-empon & 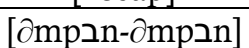 \\
\hline
\end{tabular}




\begin{tabular}{|c|c|c|}
\hline 16. & kupat & {$[$ kupat] } \\
\hline 17. & lepet & {$[1 \partial \mathrm{p} \partial \mathrm{t}]$} \\
\hline 18. & banyu & {$[$ bañu] } \\
\hline 19. & cidhuk & [cidhU?] \\
\hline 20. & wajid & [wajId] \\
\hline
\end{tabular}

Data (1) s.d (20) merupakan leksikon bentuk dasar. Berdasarkan distribusinya leksikon-leksikon tersebut termasuk ke dalam morfem bebas karena dapat berdiri sendiri sebagai kata. Berdasarkan satuan gramatikalnya leksikon di atas hanya memiliki satu morfem sehingga tergolong ke dalam bentuk monomorfemis.

Satuan lingual yang berbentuk kata kerja (verba) dalam tradisi Ngalungi Sapi berjumlah 2 data yang diuraikan sebagai berikut.

Tabel 2. Satuan Lingual Berbentuk Kata Kerja

\begin{tabular}{|c|c|c|}
\hline No. & Kata & Fonetik \\
\hline 21. & Mbunteli & {$[$ mbunt $\partial l i]$} \\
\hline 22. & Kondangan & {$[$ kondanan $]$} \\
\hline
\end{tabular}

Data (21) merupakan leksikon turunan yang tergolong dalam polimorfemis. Berdasarkan unsur pembentuknya, leksikon mbunteli terdiri atas tiga morfem. Morfem tersebut terdiri atas morfem bebas buntel dan morfem terikat /-i/. Leksikon tersebut mengalami proses morfologi yaitu morfem bebas buntel mendapat prefiks / $\mathrm{N}$-/ sehingga menjadi bentuk mbuntel yang kemudian mendapat sufiks /-i/ sehingga menjadi mbunteli. Leksikon mbunteli termasuk kategori verba yang bermakna melakukan kegiatan membungkus berulang kali.

Data (22) merupakan leksikon turunan yang tergolong dalam polimorfemis. Berdasarkan unsur pembentuknya, leksikon kondangan terdiri atas dua morfem. Morfem tersebut terdiri atas morfem bebas kondang dan morfem terikat /-an/. Leksikon tersebut mengalami proses morfologi yaitu morfem bebas kondang mendapat sufiks /-an/ sehingga menjadi bentuk kondangan. Leksikon kondangan termasuk kategori verba yang bermakna melakukan kegiatan kondangan atau kenduri.

Frasa

Keraf (dalam Ba'dulu dan Herman 2005:58) menyatakan bahwa pada dasarnya frasa adalah satuan yang terdiri dari dua kata atau lebih yang secara gramatikal bernilai sama dengan sebuah kata yang tidak bisa berfungsi sebagai subjek atau predikat dalam konstruksi tersebut.

Satuan lingual yang berbentuk frasa dalam tradisi Ngalungi Sapi berjumlah 7 data yang terbagi atas kategori frasa nominal. Kategori tersebut termasuk ke dalam tipe endosentrik. Frasa-frasa tersebut yaitu diuraikan sebagai berikut.

Tabel 3. Satuan Lingual Berbentuk Frasa Nominal

\begin{tabular}{|c|c|c|}
\hline No. & Frasa & Fonetik \\
\hline 23. & godhong lontar & [godhon lontar] \\
\hline 24. & jangan semur & [janan somur] \\
\hline 25. & iwak bandeng & [iwa? band $\partial \mathrm{n}]$ \\
\hline 26. & $\begin{array}{c}\text { kembang } \\
\text { mboreh }\end{array}$ & [komban mborsh] \\
\hline 27. & lengo wangi & [léno wani] \\
\hline 28. & dadung awuk & [dadUn awU?] \\
\hline
\end{tabular}

Data (23) s.d (28) merupakan leksikon yang berasal dari gabungan dua kata pertama dan kata kedua. Kata pertama bertindak sebagai induk sedangkan kata kedua bertindak sebagai atribut. Kata pertama yang menjadi induk dalam frasa tersebut termasuk ke dalam kelas kata kategori nomina, sedangkan kata kedua yang menjadi atribut termasuk ke dalam kelas kata kategori nomina. Penggabungan dari dua kata tersebut membentuk frasa nominal yang berkategori endosentrik.

\section{Klausa}

Khairan dan Ridwan (2015:88) menjelaskan bahwa klausa adalah satuan sintaksis yang terdiri atas dua kata atau lebih yang mengandung unsur prediksi atau tersusun atas predikator dan argumen yang belum disertai oleh intonasi akhir pada ragam lisan atau tanda baca (tanda titik, tanda seru, tanda tanya) pada ragam tulisan.

Satuan lingual yang berbentuk klausa dalam tradisi Ngalungi Sapi berjumlah 15 data yang terbagi atas kategori klausa bebas dan klausa verbal. Klausa tersebut diuraikan sebagai berikut.

Tabel 4. Satuan Lingual Berbentuk Klausa

\begin{tabular}{|c|c|c|}
\hline No. & Klausa & Fonetik \\
\hline 29. & nggawe wurung & [ngawe wurun] \\
\hline 30. & mususi beras & [mususi bôras] \\
\hline 31. & ngiseni wurung & [niseni wurun] \\
\hline 32. & nggodhog kupat & [ngodhog kupat] \\
\hline 33. & mususi ketan & [mususi kotan] \\
\hline 34. & ngoceki kelapa & 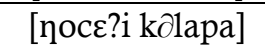 \\
\hline 35. & marud kelapa & [marud kəlapa] \\
\hline 36. & ngumbah wose & [numbah wose] \\
\hline 37. & nggodhog wose & [ngodhog wose] \\
\hline 38. & ngekum besek & 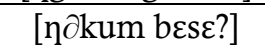 \\
\hline 39. & nyuwiri besek & [ñuwiri besc?] \\
\hline 40. & nguleni bahan & [nuloni bahan] \\
\hline 41. & $\begin{array}{l}\text { nglaburi } \\
\text { kembang }\end{array}$ & [nlaburi kəmban] \\
\hline
\end{tabular}




\begin{tabular}{|c|c|c|}
\hline 42. & ngalungke kupat & [nalunk $\partial$ kupat] \\
\hline 43. & ngedum berkat & 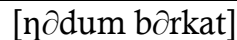 \\
\hline
\end{tabular}

Data (29) s.d (43) merupakan leksikon yang berasal dari gabungan dua kata. Kata pertama bertindak sebagai predikat sedangkan kata kedua bertindak sebagai objek. Berdasarkan strukturnya, gabungan dua kata tersebut termasuk ke dalam kategori klausa bebas. Berdasarkan kategori unsur segmental yang menjadi predikatnya termasuk ke dalam kategori klausa verbal.

\section{Wacana}

Alwi, dkk. (2003:419) menyatakan bahwa wacana adalah rentetan kalimat yang berkaitan yang menghubungkan preposisi satu dengan preposisi yang lainnya sehingga membentuk satu kesatuan.

Satuan lingual yang berbentuk wacana dalam tradisi Ngalungi Sapi terbagi atas 2 data yang berupa doa saat prosesi Ngalungi Sapi berlangsung. Doa-doa tersebut yaitu sebagai berikut.

(44) Bismillahirohmanirohim, iki dinane Jumat paing bar tandur, mbrokohi sapine, weduse kersane ngredo dadi mberah, selamet ora ono alangan apa-apa. Njaluk karo sing kuwoso supaya ngredo dadi pirang-pirang, nduwe rejeki sing akeh, selamet.

Wacana di atas terdiri atas dua kalimat (1) Bismillahirohmanirohim, iki dinane Jumat paing bar tandur, mbrokohi sapine, weduse kersane ngredo dadi mberah, selamet ora ono alangan apa-apa dan (2)Njaluk karo sing kuwoso supaya ngredo dadi pirang-pirang, nduwe rejeki sing akeh, selamet.

Pada kalimat pertama digunakan untuk menegaskan maksud dan tujuan bahwa pemilik hewan ternak melakukan selametan yang berbentuk ngalungi sapi tersebut dengan harapan agar sapi dan kambing yang dimiliki dapat berkembangbiak lebih banyak dan selalu dalam keadaan sehat dan selamat. Untuk kalimat kedua tidak jauh berbeda, masih dengan maksud supaya hewan peliharaan yang dimiliki dapat bertambah banyak, memiliki rezeki yang lancar dan barokah serta keselamatan bagi hewan beserta pemiliknya.

(45) Para lenggah sedaya ingkang kawula hurmati, ing dinten menika malem Jumat Pahing, mbah Watini sak keluarga menika badhe ngalungi lembu nipun, nyelameti lembunipun. Ingkang kawula hurmati, sepindah Kanjeng Rosul, kaping kalih Nabi Sulaiman, nabine para kewan, ing pangajab mugi-mugi sedaya ingah- ingahanipun kalebet lembu, mendo saha ayam ingkang dipunsuwun supados pikantuk ridhonipun Allah. Saget pikantuk rejeki ingkang barokah kangge nglengkapi kabetahan keluarganipun. Kaping kalih mbah Watini ngaturaken agunging panuwun dumateng para rawuh, dipunsuwuni pangestu wilujeng, wilujeng donyo ngantos akhirat saha sedaya ingkang rawuh tansah sami-sami pikantuk berkahipun Allah.

Wacana di atas terdiri atas empat kalimat, yakni (1) Para lenggah sedaya ingkang kawula hurmati, ing dinten menika malem Jumat Pahing, mbah Watini sak keluarga menika badhe ngalungi lembu nipun, nyelameti lembunipun. (2) Ingkang kawula hurmati, sepindah Kanjeng Rosul, kaping kalih Nabi Sulaiman, nabine para kewan, ing pangajab mugi-mugi sedaya ingah-ingahanipun kalebet lembu, mendo saha ayam ingkang dipunsuwun supados pikantuk ridhonipun Allah. (3) Saged pikantuk rejeki ingkang barokah kangge nglengkapi kabetahan keluarganipun, dan (4) Kaping kalih mbah Watini ngaturaken agunging panuwun dumateng para rawuh, dipunsuwuni pangestu wilujeng, wilujeng donyo ngantos akhirat saha sedaya ingkang rawuh tansah sami-sami pikantuk berkahipun Allah.

Pada kalimat pertama dijelaskan bahwa pada hari Jumat Paing tersebut mbah Watini (56) mengundang tetangga untuk melakukan kenduri dalam rangka ngalungi sapi atau dengan istilah lain yaitu nyelameti hewan peliharaan, utamanya sapi. Kalimat kedua menjelaskan bahwa sang pemimpin doa tidak lupa menyebut Tuhan dan Nabi dengan harapan semoga pemilik berserta hewan peliharaannya mendapat keberkahan. Dalam kalimat ketiga mengandung doa dan harapan agar sang pemilik sapi bisa memperoleh kesehatan dan rezeki yang lancar sehingga dapat memenuhi kebutuhan keluarga. Kalimat terakhir bertujuan untuk menyampaikan rasa terimakasih mbah Watini kepada tamu yang hadir dalam kenduri serta memohon doa dari para tamu untuk keselamatan dan kesejahteraan tuan rumah.

\section{Makna Kultural Satuan Lingual Tradisi Ngalungi Sapi}

Secara garis besar, makna kultural yang terkandung dalam tradisi Ngalungi Sapi ini yaitu sebagai bentuk rasa syukur para petani kepada Tuhan atas rezeki yang telah diberikan berupa hasil panen padi. Sapi sebagai raja kaya telah membantu petani selama masa tanam. Maka dari itu, dibuatkanlah ketupat dan lepet sebagai sajian utama dalam tradisi ini. Dalam sejarah tradisi Ngalungi Sapi, ketupat dan lepet ini disimbolkan 
sebagai Dewi Sri, dewanya para tanaman. Selain bentuk syukur, masyarakat juga memohon kesehatan, keberkahan dan kelancaran untuk hewan ternak mereka dan segala upaya dalam memeliharanya.

Fungsi Satuan-Satuan Lingual Tradisi Ngalungi Sapi

Berdasarkan fungsinya, satuan lingual dalam tradisi Ngalungi Sapi dibagi menjadi empat yang akan diuraikan sebagai berikut.

Satuan Lingual dalam Tradisi Ngalungi Sapi sebagai Sarana Ritual

Tabel 5. Satuan Lingual dalam Tradisi Ngalungi sebagai Sarana Ritual

\begin{tabular}{|c|c|}
\hline Kata & Fonetik \\
\hline Kupat & [kupat] \\
\hline Lepet & {$[1 \partial \mathrm{p} \partial \mathrm{t}]$} \\
\hline Banyu & [bañu] \\
\hline Cidhuk & [cidhU?] \\
\hline Wajid & [wajId] \\
\hline Kondangan & [kondanan] \\
\hline Frasa & Fonetik \\
\hline jangan semur & [janan somur] \\
\hline kembang mboreh & 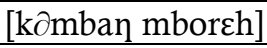 \\
\hline lengo wangi & [léno wanI] \\
\hline Klausa & Fonetik \\
\hline nglaburi kembang & [nlaburi k $\partial \mathrm{mba \eta}]$ \\
\hline ngalungke kupat & [nalunk $\partial$ kupat] \\
\hline ngedum berkat & 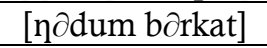 \\
\hline
\end{tabular}

Satuan lingual yang berfungsi sebagai sarana ritual yang pertama yaitu kupat dan lepet. Kupat dan lepet ini merupakan sajian utama dalam tradisi Ngalungi Sapi. Sajian ini melambangkan bersatunya Dewi Sri dan Joko Tani dalam sejarah tradisi Ngalungi Sapi.

Jangan semur hadir setelah adanya leksikon kupat dan lepet. Jangan semur merupakan sajian pelengkap ketika kupat dan lepet dihidangkan saat kenduri berlangsung. Nantinya, kupat, lepet, dan jangan semur tersebut akan dibagikan kepada tetangga yang terdekat dari rumah.

Satuan lingual yang berfungsi sebagai sarana ritual lainnya yaitu berupa uborampe yang terdiri atas kembang mboreh, lengo wangi, banyu, dan cidhuk. Uborampe tersebut muncul ketika prosesi Ngalungi Sapi berlangsung. Kembang mboreh dan lengo wangi ditaruh cidhuk kemudian dicampur dengan sedikit air. Campuran tersebut kemudian dilaburkan atau sering disebut dengan istilah nglaburi kembang ke tubuh sapi sebanyak tiga kali.

Setelah proses nglaburi selesai barulah muncul satuan lingual ngalungke kupat. Kupat dan lepet diikat sejumlah lima-lima dengan total keseluruhan 40 buah. Kemudian ikatan kupat dan lepet tersebut dikalungkan ke leher sapi selama beberapa menit secara bergantian sesuai dengan jumlah ternak yang dimiliki.

Satuan lingual lain yang muncul yaitu kondangan dan ngedum berkat. Satuan lingual ini berfungsi sebagai sarana ritual yang selanjutnya setelah proses Ngalungi Sapi selesai. Pemilik rumah akan mengundang pemimpin doa dan tetangga terdekat untuk melakukan kondangan. Sebelum kondangan dimulai, yang punya hajat akan memberikan wajid kepada tamu undangan. Di sinilah satuan lingual wajid muncul dan setelah kondangan berakhir, maka sajian kupat, lepet, dan jangan semur akan dibagikan ke tetangga terdekat. Kegiatan ini disebut dengan ngedum berkat.

Satuan Lingual dalam Tradisi Ngalungi Sapi sebagai Wujud Doa dan Harapan

Satuan lingual yang berfungsi sebagai wujud doa dan harapan ditemukan sebanyak 2 data, yaitu data (44) dan (45). Keduanya akan diuraikan sebagai berikut.

Data (44) di atas merupakan sebuah doa yang dilafalkan sang pemilik ternak sebelum memulai prosesi Ngalungi Sapi. Wacana tersebut mengandung harapan yang sangat besar bagi sang pemilik. Baik untuk hewan ternak mereka maupun untuk keluarga sendiri. Melalui tradisi Ngalungi Sapi ini, mereka berdoa dan berharap supaya hewan ternak mereka dapat bertambah banyak, diberi kesehatan, keselamatan serta rezeki yang berlimpah ruah.

Data (45) berupa doa yang dilafalkan oleh sang pemimpin kondangan. Tidak jauh berbeda dengan doa yang dilafalkan oleh pemilik sapi, doa kedua inipun mengandung banyak harapan. Dalam doanya, pemimpin menyebut Tuhan dan Nabi Sulaiman sebagai wujud harapan agar semua hewan ternak memperoleh ridho berupa kesehatan dan bertambahnya jumlah mereka. Kali ini pemimpin kondangan tak lupa mengucapkan terimakasih atas kehadiran dan memohon kesediannya untuk sama-sama mendoakan keluarga pemilik ternak agar diberi keberkahan oleh Tuhan.

Satuan Lingual dalam Tradisi Ngalungi Sapi yang Digunakan untuk Menamai Bahan-Bahan Masakan

Satuan-satuan lingual ini ditemukan sebanyak 17 data yang terdiri atas kata yang berkategori nomina dan frasa yang berkategori nominal. Data tersebut dapat diuraikan sebagai berikut.

Tabel 6. Satuan Lingual dalam Tradisi Ngalungi yang Digunakan untuk Menamai Bahan Masakan 


\begin{tabular}{|c|c|}
\hline Kata & Fonetik \\
\hline Beras & [boras] \\
\hline Janur & [janur] \\
\hline Ketan & {$[\mathrm{k} \partial \tan ]$} \\
\hline Kelapa & [kdlapa] \\
\hline Wose & [wose] \\
\hline Uyah & [uyah] \\
\hline Besek & [besc?] \\
\hline Urang & [uran] \\
\hline Tahu & [tahu] \\
\hline Endhog & 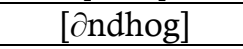 \\
\hline Mihun & [mihun] \\
\hline Pete & [pote] \\
\hline Santen & {$[\operatorname{sant} \partial \mathrm{n}]$} \\
\hline Kecap & [kecap] \\
\hline empon-empon & 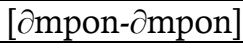 \\
\hline Frasa & Fonetik \\
\hline godhong lontar & [godhon lontar] \\
\hline iwak bandeng & [iwa? band $\partial$ n] \\
\hline
\end{tabular}

Beras merupakan bahan utama dalam isian ketupat. Tahapan awal sebenarnya adalah membuat wurung yang berbahan dasar janur atau bisa juga dengan godhong lontar. Ketiga bahan-bahan tersebut yaitu bahan-bahan yang digunakan untuk membuat kupat dalam tradisi Ngalungi Sapi di desa Sekarsari.

Setelah satuan lingual beras, janur dan daun lontar, maka muncullah satuan lingual yaitu ketan, kelapa, wose, uyah, dan besek. Kelima data tersebut digunakan untuk menamai bahan-bahan dalam pemebuatan lepet, termasuk janur. Keberadaan wose sebenarnya bisa menjadi pilihan. Ada beberapa warga yang biasanya tidak menambahkan kacang tersebut dalam pembuatan lepet. Semua bergantung selera masing-masing pembuat.

Besek digunakan sebagai tali pembungkus lepet. Besek yang sudah disiapkan harus direndam dengan air semalaman agar teksturnya lebih lemas. Setelah ditiriskan, kemudian besek di suwir-suwir menjadi bagian yang kecil supaya cukup untuk mengikat lepet yang jumlahnya banyak. Satu lepet biasanya menggunakan 3 sampai 4 suwiran besek untuk menali. Tali harus dipastikan kuat dan kencang agar tidak lepas saat proses merebus.

Setelah hidangan kupat dan lepet selesai, maka selanjutnya adalah waktunya membuat jangan semur. Masyarakat desa Sekarsari selalu memasangkan kupat dengan jangan semur. Di sinilah satuan-satuan lingual urang, tahu, endhog, mihun, pete, dan iwak bandeng muncul. Semua satuan lingual tersebut berfungsi sebagai penamaan bahan-bahan untuk membuat jangan semur. Keenam bahan tersebut akan digunakan sebagai isian jangan semur yang nantinya akan disantap dengan kupat.

Sementara itu, satuan lingual santen, kecap, dan empon-empon muncul ketika digunakan sebagai bahan bumbu dalam memasak jangan semur. Untuk mendapatkan santen, masyarakat mengerjakan semuanya secara manual. Mulai dari membeli kelapa utuh, memecah buah kelapa, mengupas kulitnya hingga memarut kelapa. Masyarakat setempat hampir tidak pernah menggunakan santan instan dalam setiap masakannya. Mereka tetap mempertahankan cara-cara yang masih manual.

Satuan Lingual dalam Tradisi Ngalungi Sapi yang Digunakan untuk Menamai Proses Memasak

Satuan lingual yang ditemukan ini berjumlah 13 data yang terdiri atas 12 data berwujud klausa dan 1 data berwujud kata. Data tersebut dapat diuraikan sebagai berikut.

Tabel 7. Satuan Lingual dalam Tradisi Ngalungi yang Digunakan untuk Menamai Proses Memasak

\begin{tabular}{|c|c|}
\hline Frasa & Fonetik \\
\hline gawe wurung & [ngawe wurun] \\
\hline mususi beras & [mususi bəras] \\
\hline ngiseni wurung & [niseni wurun] \\
\hline nggodhog kupat & [ngodhog kupat] \\
\hline mususi ketan & [mususi k $\partial \tan$ ] \\
\hline ngoceki kelapa & [noce?i kdlapa] \\
\hline marud kelapa & [marud kolapa] \\
\hline ngumbah wose & [numbah wose] \\
\hline nggodhog wose & [ngodhog wose] \\
\hline ngekum besek & [n $\partial \mathrm{kum}$ bess?] \\
\hline nyuwiri besek & [ñwirI bess?] \\
\hline nguleni bahan & [nuləni bahan] \\
\hline Kata & Fonetik \\
\hline mbunteli & [mbunt2li] \\
\hline
\end{tabular}

Nggawe wurung merupakan satuan lingual yang digunakan untuk menamai proses membuat kerangka kupat. Wurung bisa dibuat dari janur maupun godhong lontar yang dibuang lidinya dan pinggirannya, kemudian dianyam membentuk kupat. Wurung yang berbahan dasar godhong lontar memiliki aroma dan cita rasa yang khas. Jika dijual pun harganya bisa lebih tinggi. Besar kecilnya wurung kupat bergantung dengan janur atau godhong lontar yang digunakan.

Setelah nggawe wurung maka satuan lingual yang akan muncul yaitu mususi beras. Mususi beras yaitu mencuci beras yang akan digunakan untuk mengisi wurung. Beras yang digunakan bisa disesuaikan dengan banyaknya wurung yang telah dibuat. 
Ngiseni wurung yaitu mengisi kerangka ketupat dengan beras yang telah dicuci sebelumnya. Ngiseni wurung bisa dikatakan susah-susah gampang. Ketika mengisi wurung, takaran banyaknya beras yang dimasukkan harus pas. Tidak boleh kurang dan tidak boleh lebih dari setengah ukuran masing-masing wurung tersebut. Jika takaran tidak pas, bisa jadi ketupatnya nanti akan berair dan bahkan bertekstur seperti bubur.

Satuan lingual yang muncul berikutnya yaitu nggodhog kupat. Semua wurung yang telah diisi selanjutnya akan didang dengan api besar selama beberapa jam. Sebelum digunakan untuk merebus, biasanya panci akan diisi dengan potongan janur sisa pembuatan lepet. Hal ini bertujuan agar panci tidak gosong.

Mususi ketan, ngoceki kelapa, marud kelapa, ngumbah wose, nggodhog wose adalah satuan lingual yang digunakan dalam proses memasak lepet. Setelah semua bahan tersebut terkumpul, kita bisa menyiapkan wadah besar seperti nampan untuk mencampurnya.

Ngekum besek dan nyuwiri besek adalah proses selanjutnya. Ngekum besek bertujuan agar besek menjadi lemas sehingga mudah ketika digunakan untuk menali lepet. Besek disuwiri supaya cukup untuk mengikat lepet yang jumlahnya banyak.

Nguleni bahan adalah proses mencampur ketan, parutan kelapa, wose, dan garam. Setelah semua tercampur rata, maka adonan lepet siap untuk dibunteli menggunakan janur dan suwiran besek.

\section{PENUTUP \\ Simpulan}

Berdasarkan hasil penelitian dan pembahasan yang telah dilakukan, peneliti dapat merumuskan simpulan sebagai berikut. (1) Ditemukan bentuk satuan-satuan lingual berwujud kata, frasa, klausa, dan wacana dalam tradisi Ngalungi Sapi oleh masyarakat desa Sekarsari, Kecamatan Sumber, Kabupaten Rembang sejumlah 45 data. Satuan lingual tersebut terbagi menjadi empat kategori yaitu, 22 data berwujud kata yang diklasifikasikan lagi menjadi dua jenis yakni 20 data berkategori nomina dan 2 data berkategori verba; 6 data berwujud frasa yang diklasifikasikan ke dalam jenis frasa nominal yang bersifat indosentrik; 15 data berwujud klausa yang berkategori klausa bebas dan klausa verbal; dan 2 data yang berwujud wacana; (2) Makna dari satuan-satuan lingual berwujud kata, frasa, klausa, dan wacana dalam tradisi Ngalungi Sapi di desa Sekarsari, Kecamatan Sumber, Kabupaten Rembang yaitu sebagai wujud rasa syukur kepada Tuhan atas hasil cocok tanam mereka. Selain itu juga merupakan bentuk permohonan masyarakat kepada Sang Pencipta supaya hewan ternak mereka dilimpahi keberkahan, kesehatan, keselamatan, berkembangbiak dengan baik sehingga kehidupan sejahtera; (3) Fungsi dari satuan-satuan lingual berbentuk kata, frasa, klausa, dan wacana dalam tradisi Ngalungi Sapi di desa Sekarsari, Kecamatan Sumber, Kabupaten Rembang dibagi menjadi empat fungsi yaitu sebagai sarana ritual, sebagai wujud doa dan harapan, sebagai penamaan bahanbahan masakan, serta sebagai penamaan proses memasak.

\section{Saran}

Saran yang dapat disampaikan adalah (1) penelitian mengenai satuan-satuan lingual dalam tradisi Ngalungi Sapi di desa Sekarsari, Kecamatan Sumber, Kabupaten Rembang ini dapat dikembangkan lebih lanjut melalui bidang kajian yang lain, mengingat masih banyak yang bisa di gali dalam tradisi ini. (2) Masyarakat setempat khususnya kaum muda, hendaknya mempelajari seluk beluk tradisi Ngalungi Sapi lebih dalam lagi supaya mendapatkan tambahan wawasan serta dapat terus menerus melestarikannya agar tidak pudar tergerus arus modernisasi karena tradisi ini merupakan kearifan lokal yang patut dijaga. (3) Masyarakat desa Sekarsari hendaknya membuat sarana untuk mengemas satuan-satuan lingual dalam tradisi Ngalungi Sapi menjadi lebih apik tanpa mengubah esensi tradisi sehingga dapat menarik perhatian masyarakat umum untuk ikut serta mempelajari dan melestarikan tradisi tersebut.

\section{DAFTAR PUSTAKA}

Alwi, Hasan dkk. (2003). Tata Bahasa Baku Bahasa Indonesia (Edisi Ketiga). Jakarta: Balai Pustaka.

Ba'dulu, Abdul Muis dan Herman. (2005). Morfosintaksis. Jakarta: Rineka Cipta.

Fauza, Nanda. (2010). Istilah-Istilah Sesaji Upacara Tradisional Jamasan Pusaka Di Waduk Gajah Mungkur Wonogiri (Suatu Kajian Etnolinguistik). Skripsi. Universitas Sebelas Maret, Surakarta.

Fitrianingrum, W. (2016). Bahasa dalam budaya jawa terkait aktivitas pertanian padi di Desa Bangsri Kecamatan Karangpandan Kabupaten Karanganyar (kajian etnolinguistik). Skripsi. Universitas Sebelas Maret. Surakarta.

Hanifah, L., Rahayu, I. A., \& Rinata, S. (2019). Bentuk Istilah-Istilah Upacara Panggih Pernikahan Adat Jawa: Kajian Etnolinguistik. LITE: Jurnal Bahasa, Sastra, dan Budaya, 15(2), 204-216.

Kamsiadi, Bebetho Frederick Dkk. (2013). "IstilahIstilah Yang Digunakan Pada Acara Ritual Petik Pari Oleh Masyarakat Jawa Di Desa 
Sumberpucung Kabupaten Malang (Kajian Etnolinguistik)". Publika Budaya. November 2013. Volume 1. Nomor 1:64-78. Jember: Universitas Jember.

Kesuma, Tri Mastoyo Jati. (2007). Pengantar (Metode) Penelitian Bahasa. Yogyakarta: Caravatibooks.

Khairan, Miftahul dan Sakura Ridwan. (2015). Sintaksia (Memahami Satuan Kalimat Prespektif Fungsi). Jakarta: Bumi Aksara.

Komariyah, S. (2018). Leksikon Peralatan Rumah Tangga Berbahan Bambu Di Kabupaten Magetan

(Kajian

Etnolinguistik). Paramasastra, 5 (1)

Marawiranu, Y. A. (2016). Produk Kata-Kata Industri Kreatif Cak Cuk Kata Kota Kita: Kajian Etnolinguistik. Skripsi. Universitas Airlangga.

Purwanti, Retno Heni. (2018). Satuan-Satuan Lingual dalam Perayaan Imlek Masyarakat Tionghoa: Kajian Etnolinguistik di Kecamatan Gombong. Skripsi. Universitas Negeri Semarang.

Purwanto, Wahyu. (2013). "Peran Budaya Usaha Tani Ternak Sapi Potong Dalam Kehidupan Ekonomi Petani Desa (Studi Kasus Di Desa Muraharjo Kecamatan Kunduran Kabupaten Blora)". Solidarity. April 2013. Volume 2. Nomor 2:129-135. Semarang: Universitas Negeri Semarang.

Safitri, Eqlima Dwiana. (2014). Nilai Dan Fungsi Tradisi Jumat Pahing Di Dusun Kawangan Kecamatan Ngadirejo Kabupaten Temanggung. Skripsi. Universitas Islam Negeri Kalijaga, Yogyakarta.

Sari, D. M. (2017). Nilai Filosofis dalam Leksikon Batik Demak di Kabupaten Demak (Kajian Etnolinguistik). Skripsi. Universitas Negeri Semarang).

Sari, Teky Dwi Ana. (2006). Upacara Bersih Desa Tanjung Sari Di Dukuh Dlimas Desa Dlimas
Kecamatan Ceper Kabupaten Klaten (Kajian Bentuk, Fungsi Dan Makna Simbolik). Tesis. Universitas Negeri Semarang.

Setiani, P. E., Sudaryat, Y., \& Kuswari, U. (2018). Leksikon anyaman bambu di kecamatan Pacet kabupaten Bandung (Kajian Etnolinguistik). Lokabasa, 9(1), 63-72.

Suarsini, N. N. (2018). Tradisi Ngelawang pada Hari Raya Kuningan di Desa Pakraman Asak Pagutan: Sebuah Kajian Etnolinguistik. Jurnal Mabasindo: Jurnal Bahasa dan Sastra Indonesia, 2(2).

Sugianto, Alip. (2015). Gaya Bahasa dan Budaya Mantra Warok Reyog Ponorogo (Kajian Etnolinguistik). Prosiding Seminar Nasional Pendidikan "Inovasi Pembelajaran untuk Pendidikan Berkemajuan". FKIP Universitas Muhammadiyah Ponorogo.

Sukri, M. (2018). Leksikon Dalam Adat Perkawinan Masyarakat Suku Sasak Di Kabupaten Lombok Utara: Sebuah Kajian Etnolinguistik. Jurnal Mabasindo: Jurnal Bahasa Dan Sastra Indonesia, 2(2).

Wulandari, A., Marsono, M., \& Suhandono, S. (2018). Pandangan Penutur Bahasa Jawa terhadap Cacar: Kajian Etnolinguistik. Mozaik Humaniora, 18 (1), 15-32. 